\title{
Palliative Care, Other Than Pain and Hospice
}

National Cancer Institute

\section{Source}

National Cancer Institute. Palliative Care, Other Than Pain and Hospice. NCI Thesaurus.

Code C15830.

Supportive care that is not hospice or pain relief 